\title{
Modified Approach Using Mentha arvensis in the Synthesis of ZnO Nanoparticles-Textural, Structural, and Photocatalytic Properties
}

\author{
Daniela Stoyanova ${ }^{1, *}$, Irina Stambolova ${ }^{1}$, Vladimir Blaskov ${ }^{1,2}$, Petya Georgieva ${ }^{1}$, Maria Shipochka ${ }^{1}$, \\ Katerina Zaharieva ${ }^{3}$, Ognian Dimitrov ${ }^{4}{ }^{(}$, Pavel Markov ${ }^{1}$, Vanya Dyakova ${ }^{2}$, Yoanna Kostova ${ }^{2}$, \\ Ralitsa Mladenova ${ }^{5}$, George Tzvetkov ${ }^{6}$, Nelly Boshkova ${ }^{7}$ and Nikolai Boshkov ${ }^{7}$
}

check for updates

Citation: Stoyanova, D.; Stambolova, I.; Blaskov, V.; Georgieva, P.;

Shipochka, M.; Zaharieva, K.;

Dimitrov, O.; Markov, P.; Dyakova, V.;

Kostova, Y.; et al. Modified Approach

Using Mentha arvensis in the

Synthesis of $\mathrm{ZnO}$

Nanoparticles-Textural, Structural, and Photocatalytic Properties. Appl. Sci. 2022, 12, 1096. https://doi.org/ 10.3390/app12031096

Academic Editors: Antonio Zucca, Maria Milanova and Martin Tsvetkov

Received: 28 December 2021

Accepted: 18 January 2022

Published: 21 January 2022

Publisher's Note: MDPI stays neutral with regard to jurisdictional claims in published maps and institutional affiliations.

Copyright: (C) 2022 by the authors. Licensee MDPI, Basel, Switzerland. This article is an open access article distributed under the terms and conditions of the Creative Commons Attribution (CC BY) license (https:// creativecommons.org/licenses/by/ $4.0 /)$.
1 Institute of General and Inorganic Chemistry, Bulgarian Academy of Sciences, “Acad. G. Bonchev” St. Bl. 11, 1113 Sofia, Bulgaria; stambolova@yahoo.com (I.S.); vblaskov@abv.bg (V.B.); peti@gbg.bg (P.G.); shipochka@svr.igic.bas.bg (M.S.); pvlmarkov@svr.igic.bas.bg (P.M.)

2 Institute of Metal Science, Equipment and Technologies with Hydro- and Aerodynamics Centre "Acad. A. Balevski", Bulgarian Academy of Sciences, Shipchenski Prohod Blvd. 67, 1574 Sofia, Bulgaria; vdiakova@ims.bas.bg (V.D.); joannahristova@abv.bg (Y.K.)

3 Institute of Mineralogy and Crystallography "Acad. Ivan Kostov", Bulgarian Academy of Sciences, "Acad. G. Bonchev" St., Bl. 107, 1113 Sofia, Bulgaria; zaharieva@imc.bas.bg

4 Institute of Electrochemistry and Energy Systems, Bulgarian Academy of Sciences, "Acad. G. Bonchev" St., B1. 10, 1113 Sofia, Bulgaria; ognian.dimitrov@iees.bas.bg

5 Institute of Catalysis, Bulgarian Academy of Sciences, "Acad. G. Bonchev" St., B1. 11, 1113 Sofia, Bulgaria; ralitsa@ic.bas.bg

6 Faculty of Chemistry and Pharmacy, Sofia University" St. Kliment Ohridski", 1 James Bourchier Blvd., 1164 Sofia, Bulgaria; george.tzvetkov@gmail.com

7 Institute of Physical Chemistry "Acad. R. Kaishev", Bulgarian Academy of Sciences, Acad. G. Bonchev" St., Bl. 11, 1113 Sofia, Bulgaria; nelly.boshkova@ipc.bas.bg (N.B.); NBoshkov@ipc.bas.bg (N.B.)

* Correspondence: dsto@svr.igic.bas.bg

\begin{abstract}
Zinc oxide arouses considerable interest since it has many applications-in microelectronics, environmental decontaminations, biomedicine, photocatalysis, corrosion, etc. The present investigation describes the green synthesis of nanosized $\mathrm{ZnO}$ particles using a low-cost, ecologically friendly approach compared to the classical methods, which are aimed at limiting their harmful effects on the environment. In this study, $\mathrm{ZnO}$ nanoparticles were prepared using an extract of Mentha arvensis (MA) leaves as a stabilizing/reducing agent, followed by hydrothermal treatment at $180{ }^{\circ} \mathrm{C}$. The resulting powder samples were characterized by X-ray diffraction (XRD) phase analysis, infrared spectroscopy (IRS), scanning electron microscopy (SEM), and electron paramagnetic resonance (EPR). The specific surface area and pore size distribution were measured by the Brunauer-Emmett-Taylor (BET) method. Electronic paramagnetic resonance spectra were recorded at room temperature and at $123 \mathrm{~K}$ by a JEOL JES-FA 100 EPR spectrometer. The intensity of the bands within the range of $400-1700 \mathrm{~cm}^{-1}$ for biosynthesized $\mathrm{ZnO}(\mathrm{BS}-\mathrm{Zn})$ powders decreased with the increase in the Mentha arvensis extract concentration. Upon increasing the plant extract concentration, the relative proportion of mesopores in the BS-Zn samples also increased. It was established that the photocatalytic performance of the biosynthesized powders was dependent on the MA concentration in the precursor solution. According to EPR and PL analyses, it was proved that there was a presence of singly ionized oxygen vacancies $\left(\mathrm{V}_{0}^{+}\right)$and zinc interstitials $\left(\mathrm{Zn}_{\mathrm{i}}\right)$. The use of the plant extract led to changes in the morphology, phase composition, and structure of the $\mathrm{ZnO}$ particles, which were responsible for the increased photocatalytic rate of discoloration of Malachite Green dye.
\end{abstract}

Keywords: zinc oxide; photocatalysis; defect structure; hydrozincite 


\section{Introduction}

Generally, metal oxide particles have wide practical applications and can be applied in biomedicine, different tools, batteries, heavy industrial equipment, pipes and fittings for offshore applications, for antibacterial and photocatalytic purposes, as well as to enhance the life of base materials. One of the most widely used metal oxides is $\mathrm{ZnO}$. The latter has been studied intensively with respect to its application in various devices: transistors, sensors, catalysts/photocatalysts, Ultra Violet (UV) adsorbers, pigments, photoelectrodes, solar cells), antibacterial coating and packaging, in the cosmetic industry as sunscreens, in medicine (drug delivery), etc., due to its excellent physicochemical, electronic, and antibacterial characteristics [1-5].

Additionally, the incorporation of nano- $\mathrm{ZnO}$ and nanosilica can yield self-cleaning epoxy coatings with desirable properties, such as easy sliding of water droplets. Other researchers have incorporated nanosilica, $\mathrm{ZnO}$, alumina, and similar additives to improve the mechanical strength of epoxy coatings and to block UV light [6-12]. Among the various metal oxides, $\mathrm{ZnO}$ is considered to be one of the most promising materials for photocatalytic and corrosion protective applications, especially after additional polymeric modifications [13-15]. Additionally, this compound ensures an enhanced protective ability by forming corrosion products with barrier properties on the metal surface [15].

$\mathrm{ZnO}$ is a well-known II-VI wide band gap $(3.2 \mathrm{eV})$ semiconductor material. The electronic structure and the valence state of the zinc and oxygen ions are influenced by the nature and concentration of intrinsic and extrinsic defects. Different point defects could occur in the crystal lattice of $\mathrm{ZnO}$ : oxygen vacancies $\left(\mathrm{V}_{0}\right)$, oxygen interstitials $\left(\mathrm{O}_{\mathrm{i}}\right)$, zinc vacancies $\left(\mathrm{V}_{\mathrm{Zn}}\right)$, zinc interstitials $\left(\mathrm{Zn}_{\mathrm{i}}\right)$, etc. [16].

One of the most important applications of $\mathrm{ZnO}$ is in the field of heterogeneous photocatalysis for the removal of various organic pollutants in waste waters and air [17]. The UV irradiation of the semiconductor photocatalysts initiates a reaction by producing photoexcited electron-hole pairs, which can react further with the adsorbed pollutant molecules. As a result of the oxy/redox processes, complete mineralization of the contaminants occurs [18]. Various synthesis methods of photo-catalytically active $\mathrm{ZnO}$ nanoparticles (ZNP) have been applied: thermal evaporation [19], chemical vapor deposition (CVD) [20], mechano-chemical preparation [21], sol-gel [22] spray pyrolysis [23], hydrothermal synthesis [24], precipitation [25], etc. Most of the abovementioned conventional procedures are complex, based on the application of toxic reducing and stabilizing agents. In addition, the particles produced by the classical chemical methods tend to form agglomerates. The hydrothermal approach is a simple low-cost method that allows the preparation of nanosized powders, which have a high degree of crystallinity and high chemical activity. In this technique, the morphology of nanoparticles can be controlled by optimizing various reaction conditions [26].

The so-called "green synthesis" of particles, using bio-organisms (plants, algae, and microbes) is a relatively new strategy for the preparation of ZNP and other oxide particles. It is environmentally friendly, has a low cost, and it allows the preparation of stable nano-sized particles. The use of hazardous organic compounds (solvents and stabilizing agents) is avoided. The main constituents in the plants: polyphenols, terpenoids, etc., act as stabilizing and reducing agents. The plant-mediated synthesis of $\mathrm{ZnO}$ particles is a complex process. According to Huang et al. [27], it consists of the movement of delocalized pi-electrons in aromatic rings, hydroxyl chelation to $\mathrm{Zn}$ ions, oxidation of hydroxyl groups, and reduction of $\mathrm{Zn}$ ions. The plant extract plays a capping role in $\mathrm{ZnO}$ synthesis, thus preventing agglomeration processes. The use of biological templates changes the final surface properties of $\mathrm{ZnO}$ by controlling of the morphology and size. Many parameters influence the particle shape and size: temperature, reaction time, $\mathrm{pH}$, type, and concentration of the both the zinc source and plant [28]. Various plants and exotic fruits have been used in $\mathrm{ZnO}$ biosynthesized particles: Coriandrum sativum [29], Garzinia mangostana [30], Cannabis sativa [31], Brassica oleracea [32], Cassia fistula [33], Mentha spicata [34], Mentha pulegium [35], etc. Mentha arvensis (belongs to the family Lamiaceae) is widely applied in medicine and in pharmaceuticals for the 
treatment of infectious diseases due to its antioxidizing and antimicrobial properties, which appear as a result of presence of different organic compounds: terpenoids, flavonoids, etc. Ahmad et al. [36] studied the antimicrobial properties of $\mathrm{TiO}_{2}$ particles obtained by Mentha arvensis extract-mediated synthesis. Another research group used Mentha arvensis for synthesis of stable Au nanoparticles [37]. According to the best of our knowledge, studies concerning the photocatalytic properties of $\mathrm{ZnO}$ nanoparticles, synthesized with Mentha arvensis as a reducing agent, are very scarce. Manuja et al. prepared ZnO for energy applications, by means of Mentha arvensis leaves [38]. In the present article, we show the successful application of Mentha arvensis leaf extract in the synthesis of $\mathrm{ZnO}$ particles, possessing enhanced photocatalytic efficiency. The aim of the present research work is (1) to determine whether Mentha arvensis-mediated hydrothermal $\mathrm{ZnO}$ powders are efficient photocatalysts for discoloration of water contaminated with Malachite Green (MG dye) and (2) to check whether the application of the plant extract contributes suitable structural and textural characteristics of the photocatalytic material providing the potential to obtain $\mathrm{ZnO}$ with combined protective and photocatalytic properties.

\section{Materials and Methods}

\subsection{Chemicals}

Zinc acetate $\mathrm{Zn}\left(\mathrm{CH}_{3} \mathrm{COO}\right)_{2} \cdot 2 \mathrm{H}_{2} \mathrm{O}$ (p.a.; Valerus Ltd., Sofia, Bulgaria) and urea $\mathrm{CH}_{4} \mathrm{~N}_{2} \mathrm{O}$ (p.a.; Valerus Ltd.) were used as a zinc precursor and precipitating reagent.

\subsection{Preparation of Mentha arvensis (MA) Leaf Extract}

The Mentha arvensis (MA) leaves (from a region located in the north of Bulgaria) were washed and left to dry; $12 \mathrm{~g}$ of MA leaves was ground into powder using a mortar, and the powder was mixed with $230 \mathrm{ml}$ double-distilled water. The mixture was heated at $60{ }^{\circ} \mathrm{C}$ for 10 min under continuous magnetic stirring. In order to obtain the final extract, the solution was centrifuged at $4000 \times$ rpm for $20 \mathrm{~min}$, after which the material was filtered by KA2 filter paper (100 pcs, PAPIRNA Perstejn s.r.o., Perstejn, Chech Republic).

\subsection{Preparation of Green Synthesized $\mathrm{ZnO}$ Particles}

Zinc acetate aqueous solution $(0.2 \mathrm{M})$ and urea aqueous solution $(0.6 \mathrm{M})$ were used as the initial precursor solution and precipitating reagent. According to the research work of Mohammadi et al., the highest adsorption of $\mathrm{ZnO}$ particles occurs at $\mathrm{pH}=8$ [39], and for this reason, we adjusted $\mathrm{pH}$ of the solution to 8 (using ammonium hydroxide). Zinc precursor solution was poured into beaker, and then the evaluated quantity of the as-prepared extract MA was added and stirred at a rate of $200 \mathrm{rpm}$. The resulting mixture was transferred into an autoclave, and it was maintained at $180^{\circ} \mathrm{C}$. The so-obtained precipitates were washed and dried in an oven, after which they were treated at $170^{\circ} \mathrm{C}$ for $3 \mathrm{~h}$. Powders containing 0\% MA, 10\% MA, and 20\% MA are denoted as G0, G1, and G2 respectively. Figure 1a represents the experimental scheme of the Mentha arvensis approach for $\mathrm{ZnO}$ synthesis.

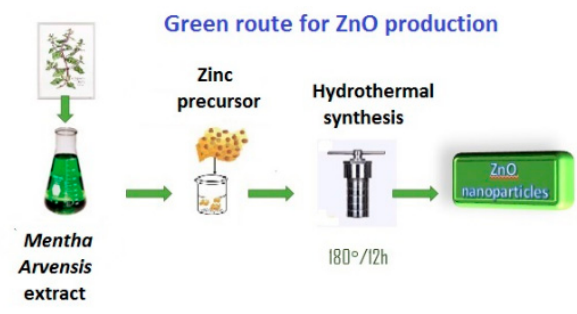

(a)

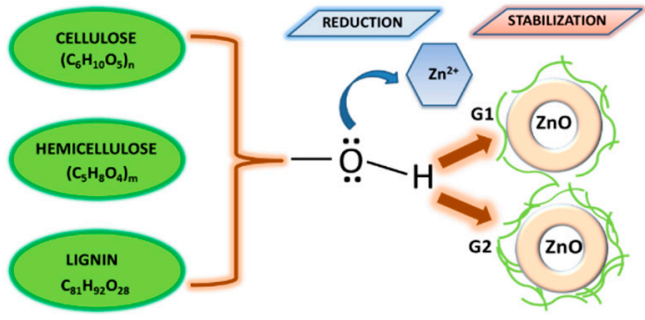

(b)

Figure 1. Experimental scheme of bio-mediated $\mathrm{ZnO}$ powder preparation-(a); scheme illustrating the reducing/stabilizing role of the Mentha arvensis extract-(b). 
It has been proved that the Mentha arvensis extract consists mainly of cellulose (38-42\%), hemicellulose (27-30\%) and lignin (12-8\%) [38]. During the biosynthesis, an interaction between the hydroxyl groups and $\mathrm{Zn}^{2+}$ ions leads to the reduction and formation of the zinc complex (Figure 1b). Then, a reaction occurs between the reduced zinc and the dissolved oxygen in the reaction mixture, which leads to conversion into $\mathrm{ZnO}$. The final stage is the nucleation and stabilization of zinc oxide.

\subsection{Characterization of the Samples}

The phase composition of the samples was investigated by means of X-ray diffraction (XRD) using a Bruker D2 Phaser diffractometer, Karlsruhe, Germany ( $\mathrm{Cu}$ K $\alpha$ radiation; $\lambda=0.154056 \mathrm{~nm}$ at $40 \mathrm{kV})$.

An automated apparatus NOVA Win-CFR Quantachrom-Gas Sorption System, Florida, USA was applied to estimate the pore size distribution (DFT method).

The infrared spectra (4000-400 $\mathrm{cm}^{-1}$ region) were registered using a Thermo Scientific Nicolet iS5 Fourier-transform IR spectrometer (KBr pellets, resolution of $2 \mathrm{~cm}^{-1}$ ).

Scanning electron microscopy (SEM) micrographs were recorded on a JEOL JEM200CX at an accelerating voltage of $80 \mathrm{keV}$. The TEM observations were carried out using a transmission electron microscope, JEOL JEM 1011, at an accelerating voltage of $100 \mathrm{kV}$. Prior to the TEM measurements, the powders were suspended in ethanol and were then deposited on a carbon replica and evaporated on a copper grid $(\mathrm{d}=3 \mathrm{~mm})$. For a better contrast, the grid with the sample was re-coated with porous carbon.

Room-temperature photoluminescence (PL) of powders were performed by means of a Varian Cary Eclipse spectrofluorimeter (excitation wavelength of $325 \mathrm{~nm}$ ).

In order to obtain information about the chemical composition of the samples, EDX analyses were carried out by means of a Quantax 220 Bruker apparatus.

Electronic paramagnetic resonance spectra (EPR) were recorded at room temperature by a JEOL JES-FA 100 EPR spectrometer operating in the X-band with a standard TE 011 cylindrical resonator at a modulation frequency of $100 \mathrm{kHz}$, microwave power of $3 \mathrm{~mW}$, modulation amplitude of $0.2 \mathrm{mT}$, time constant of $0.1 \mathrm{~s}$, and sweep time of $2 \mathrm{~min}$.

The XPS measurements were carried out on AXIS Supra electron spectrometer (Kratos Analitycal Ltd., AlK $\alpha$ radiation, photon energy of $1486.6 \mathrm{eV}$ ) using the commercial dataprocessing software of Kratos Analytical Ltd. The binding energies (BE) were determined with an accuracy of $\pm 0.1 \mathrm{eV}$. The chemical compositions in the depth of the films were determined monitoring the areas and binding energies of the C1s, O1s, and Zn2p photoelectron peaks.

\subsection{Photocatalytic Activity Tests}

The photocatalytic properties were tested using MG as a model pollutant dye (10 ppm dissolved in $150 \mathrm{ml}$ DD water) under polychromatic UV-A illumination $\left(\lambda_{\max }=365 \mathrm{~nm}\right.$, BLB lamp of power of $18 \mathrm{~W}$, light intensity of $\left.5 \times 10^{-5} \mathrm{~W} / \mathrm{cm}^{2}\right)$. The course of the oxidative discoloration reaction was monitored by a UV-visible absorbance spectrophotometer UV1600PC (wavelength range 200-800 nm). The samples were left under dark conditions for $30 \mathrm{~min}$, after which the irradiation was switched on to obtain adsorption-desorption equilibrium.

\subsection{Recyclability Tests}

The recyclability of the biosynthesized samples was estimated by performing three consecutive cycles using the samples that represented the best results. After each cycle, the powder was removed from the dye solution and it was washed with deionized water and dried at $60{ }^{\circ} \mathrm{C}$. 


\section{Results and Discussion}

The X-ray diffraction patterns of the reference $\mathrm{ZnO}$ sample after treatment at $170{ }^{\circ} \mathrm{C}$ showed narrow and sharp diffraction peaks, corresponding to a well-crystallized wurtzite polycrystalline phase (Figure 2: inset).

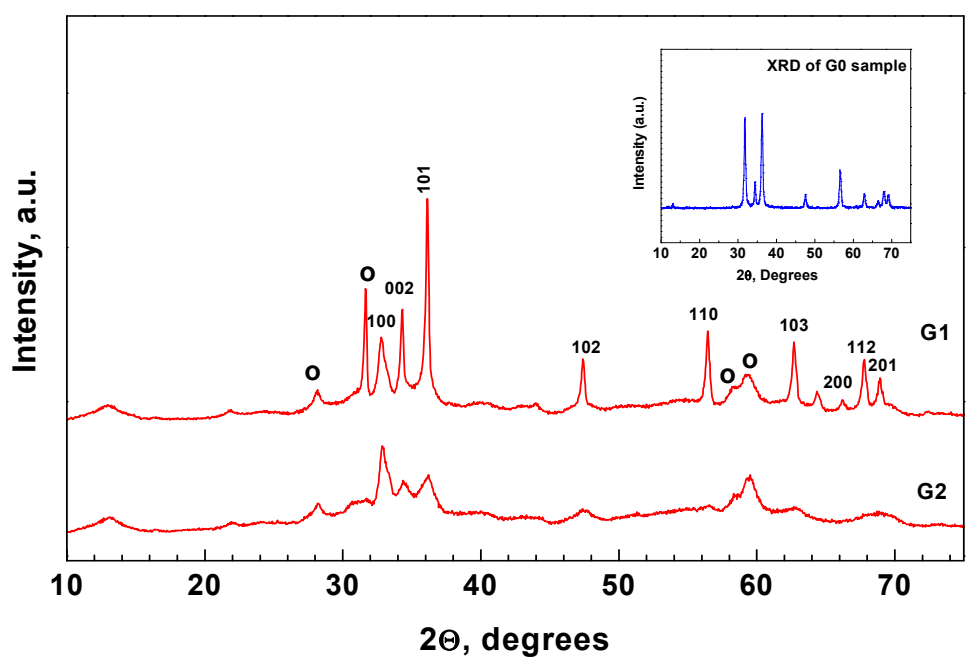

Figure 2. XRD patterns of bio-mediated samples and the reference sample G0 (inset); o-Zinc Hydroxide Carbonate (Hydrozincite) $\mathrm{Zn}_{5}(\mathrm{OH})_{6}\left(\mathrm{CO}_{3}\right)_{2}$, PDF 72-1100, Wurtzite-PDF 89-7102.

The plant extract influenced the phase composition of the biosynthesized samples: the powders consisted of wurtzite phase and a small quantity of hydroxide zinc carbonate (Figure 2). The increased concentration of the MA extract resulted in a broadening of the peaks, i.e., it suppressed the crystallization degree (the (101) peak intensity decreased significantly). The hydroxide zinc carbonate phase became almost amorphous. Similar results were obtained by Elumalaia et al. for plant-mediated $\mathrm{ZnO}$, using $V$. trifolia extract [40]. The mean crystallite size (D), lattice strain $(\varepsilon)$, and unit cell parameter (a) of the zinc oxide and hydrozincite phases are represented in Table 1.

Table 1. Calculated values of the mean crystallite size (D), lattice strain $(\varepsilon)$, and unit cell parameter (a) of the wurtzite and hydrozincite crystallographic phases.

\begin{tabular}{ccccc}
\hline Sample & Phase & $\mathbf{D}, \mathbf{n m}$ & $\boldsymbol{\varepsilon} \times \mathbf{1 0}^{-\mathbf{3}}, \mathbf{a . u}$ & $\mathbf{a}, \mathbf{\AA}$ \\
\hline \multirow{2}{*}{ G0 } & Wurtzite & 14.8 & 1.1 & 3.249 \\
\hline \multirow{2}{*}{ G1 } & Wurtzite & 9.8 & 4.2 & 3.257 \\
\cline { 2 - 5 } & Hydrozincite & 11.5 & 3.6 & 13.714 \\
\hline \multirow{2}{*}{ G2 } & Wurtzite & 8.6 (left) & 3.3 & 3.245 \\
\cline { 2 - 5 } & Hydrozincite & 7.6 & 4.2 & 13.720 \\
\hline
\end{tabular}

These parameters were calculated by the PowderCell 2.4 program [41] and using the Williamson-Hall equation [42], and they are listed in Table 1. The average crystallite size of the wurtzite and hydrozincite phases decreased with increasing amount of the MA plant extract used for the preparation of samples. The mean crystallite size of the $\mathrm{ZnO}$ and hydrozincite phases in G2 was smaller than that in sample G1 and reference $\mathrm{ZnO}$ (Meron Girma Demissie et al.), proving that the crystallite sizes of the green synthesized $\mathrm{ZnO}$ decreased with increasing amount of the plant extract [43]. The higher concentration of the plant extract led to effective stabilizing and capping of the $\mathrm{ZnO}$ nanoparticles, thus preventing particle aggregation and the particle growth rate.

Hydroxide Carbonate (Hydrozincite) $\mathrm{Zn} 5(\mathrm{OH})_{6}\left(\mathrm{CO}_{3}\right)_{2}$, PDF 72-1100, Wurtzite-PDF 89-7102. 
Figure 3a represents the chrysanthemum-like morphology of the G0 sample, while Figure $3 \mathrm{~b}$ reveals a plate-like structure in aggregated form-conglomerates of the biomediated particles. Figure 4a represent the TEM of the reference sample, which consists of many aggregated particles with different sizes. When the MA extract was added as a reducing agent, the samples were mainly composed of tiny separated particles, which confirms the role of MA extract for prevention or retardation of particle agglomeration (Figure $4 \mathrm{~b}$ ). The particle size of the plant-mediated powder G1 in the TEM photograph was about 30 to $100 \mathrm{~nm}$, which is higher than that obtained by Scherrer's equation.

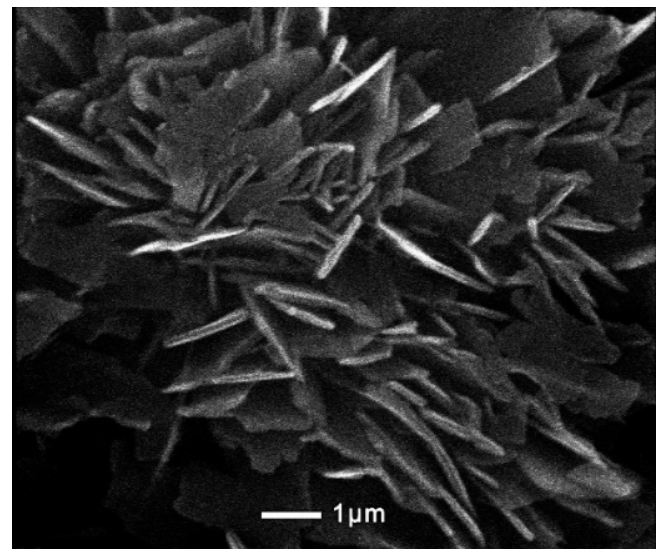

(a)

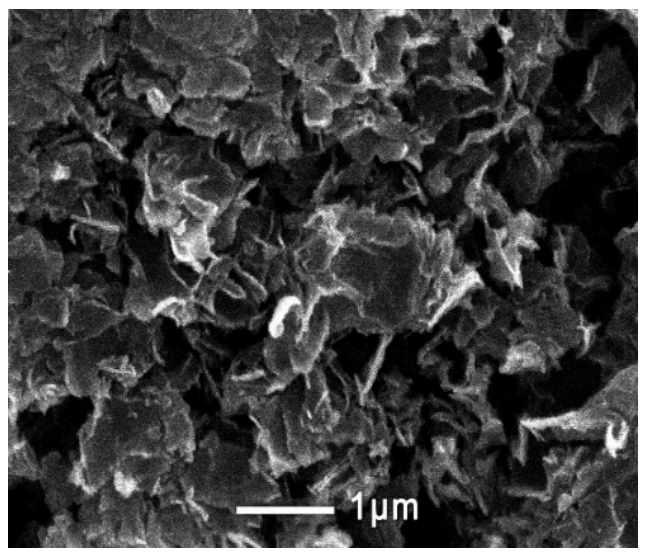

(b)

Figure 3. SEM photographs of G0 (a) and G1 (b) powders.

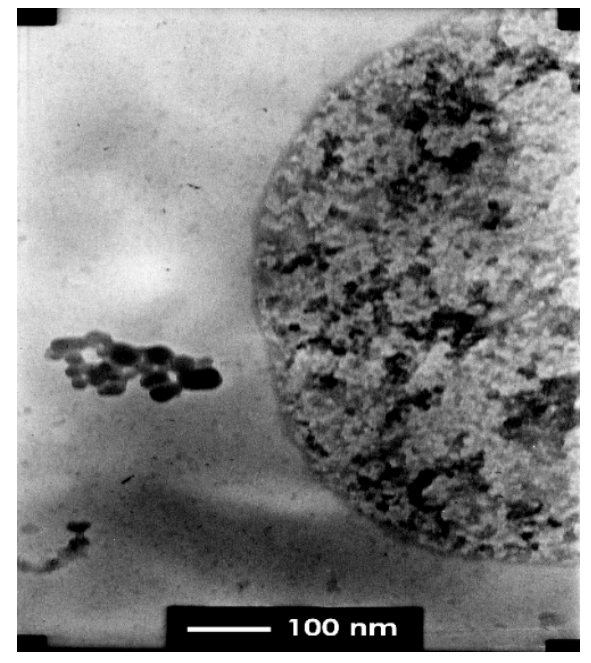

(a)

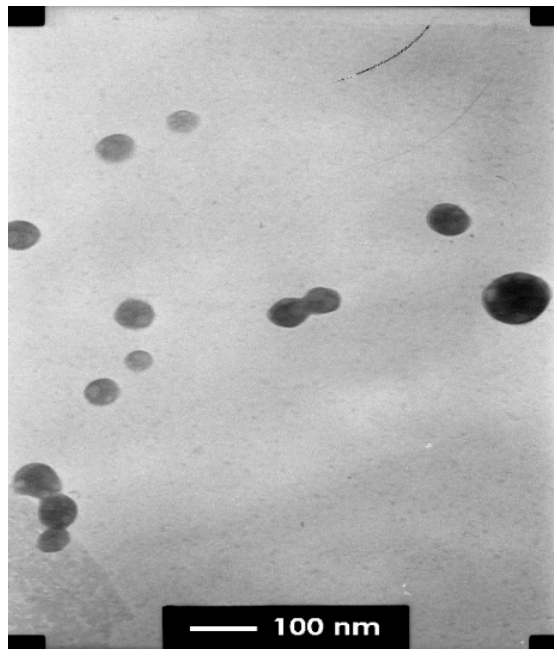

(b)

Figure 4. TEM photographs of G0 (a) and G1 (b) powders.

EDX analyses of all samples were carried out at six different points and revealed a similar elemental composition. Zinc, oxygen, and carbon only without any other elements were registered in the spectrum of the reference samples (Figure 5). 


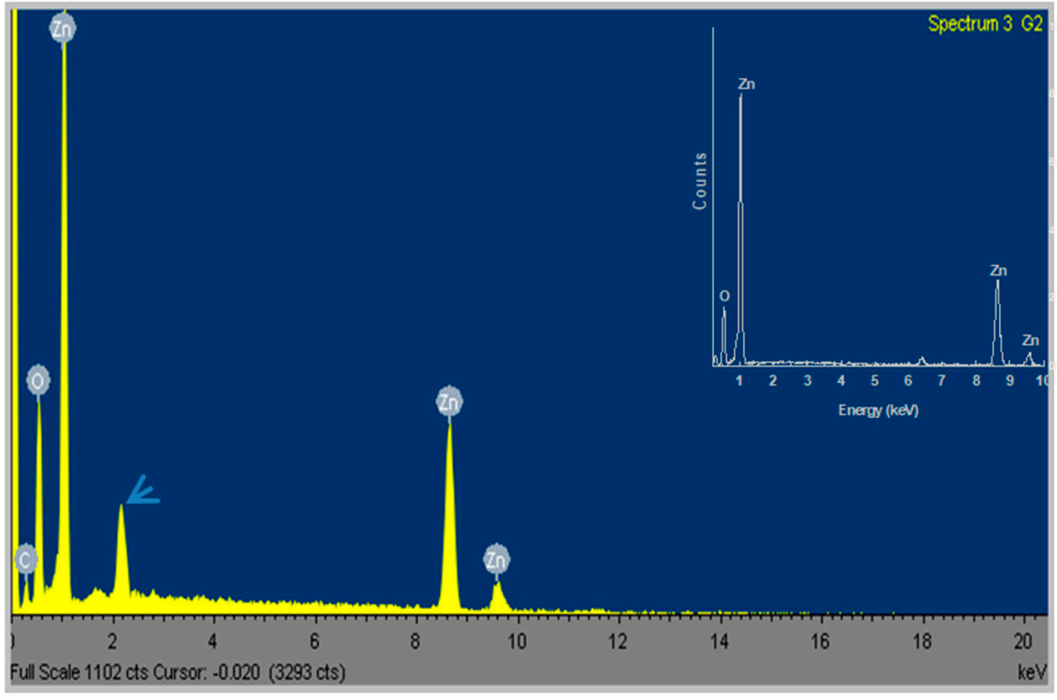

Figure 5. EDX spectrum of the plant-mediated G2 powder and the reference powder (inset); the arrow indicates $\mathrm{Au}$ originating from conductive material.

All of the samples had similar pore size distribution curves. The reference $\mathrm{ZnO}$ powders exhibited one narrow peak corresponding to micropores (size up to $10 \mathrm{~nm}$ ) and a broad area peak, corresponding to a small quantity of mesopores within the region of 20 to $50 \mathrm{~nm}$ (Figure 6).

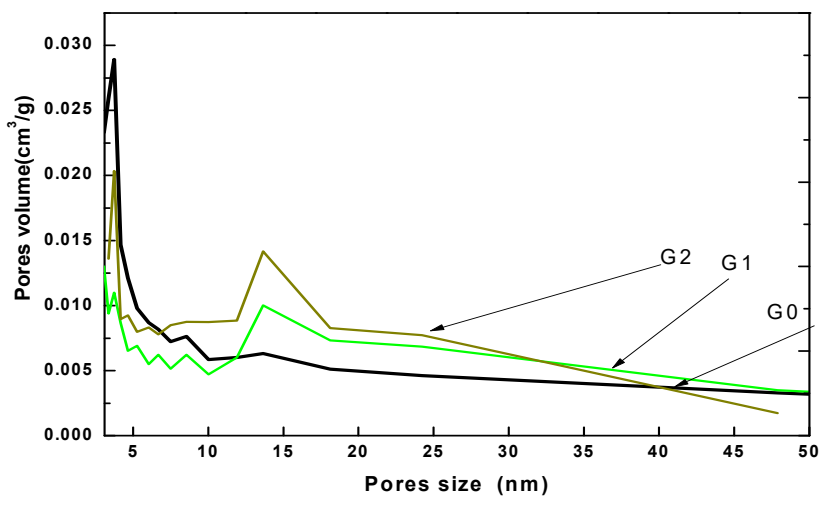

Figure 6. Pore size distribution curves of plant-mediated $\mathrm{ZnO}$ samples.

The biosynthesized samples exhibited an increased share and size of the pores in comparison to the reference powder, which were responsible for the increased specific area ( 80 and $140 \mathrm{~m}^{2} / \mathrm{g}$ for G1 and G2, respectively). The average pore size of G0 was $9.5 \mathrm{~nm}$, while the G1 and G2 powders had pores size $16 \mathrm{~nm}$ and $17 \mathrm{~nm}$, respectively.

The IR spectrum of the MA extract had a band, located at $1065 \mathrm{~cm}^{-1}$, which could be assigned to the $\mathrm{C}-\mathrm{O}$ bond from biomolecules [44] (Figure 7). The band at $1634 \mathrm{~cm}^{-1}$ belongs to an aromatic ring [45], while the one at $1573 \mathrm{~cm}^{-3}$ corresponds to the N-H bending vibration of amine or amide groups, which could be due to the presence of different phytochemical constituents [36]. 


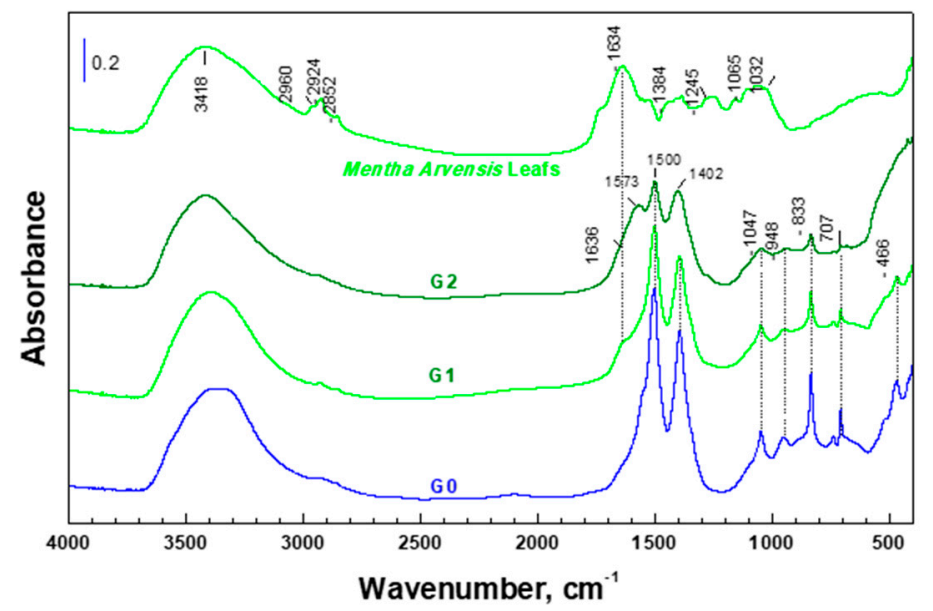

Figure 7. Infrared spectra of plant-mediated $\mathrm{ZnO}$ samples.

The band at $2960 \mathrm{~cm}^{-1}$ corresponds to asymmetric C-H stretching, while the bands at $2924 \mathrm{~cm}^{-1}$ and $2852 \mathrm{~cm}^{-1}$ correspond to saturated sp $\mathrm{s}^{3}$ carbon [46]. In the IR spectra of the particles obtained by us, a difference in the intensity of the bands within the range of 400-1700 $\mathrm{cm}^{-1}$ was observed, as it decreased with the increase in the MA extract quantity. All spectra showed broad bands in the region of $466 \mathrm{~cm}^{-1}$, which is characteristic for the formation of the $\mathrm{Zn}-\mathrm{O}$ bond. At 948 and $707 \mathrm{~cm}^{-1}$, peaks could be attributed to $\mathrm{CH}_{3}$ bending modes, while the band at $1047 \mathrm{~cm}^{-1}$ corresponds to the carbonate group [47]. The strong peaks at 1402 and $1500 \mathrm{~cm}^{-1}$ belong to carboxylate stretching modes [48]. The shoulder at $1636 \mathrm{~cm}^{-1}$ derived from the MA extract was also observed in the spectra of the G1 and G2 samples [46], while the one at $1384 \mathrm{~cm}^{-1}$ corresponds to the C-H group in an aldehyde compound [36].

EPR spectroscopy is an effective technique to identify unpaired electrons so that the surface paramagnetic defects, radicals, cations or clusters are easily detected through EPR signals. The spectrum of the G1 sample consisted of two signals, S1 and S2 (Figure 8). The $\mathrm{S} 1$ signal was recorded at $\mathrm{g}=1.9534$, which is attributed to ionized oxygen vacancy defects $\left(\mathrm{V}_{0}{ }^{+}\right)$[49]. The second signal was detected at a g-value of 1.997 (S2). According to literature data, the signal with a g-factor close to the free electron $2.0023 \mathrm{in} \mathrm{ZnO}$ refers to singly ionized oxygen vacancies $\left(\mathrm{V}_{0}{ }^{+}\right)$defects $[50,51]$.
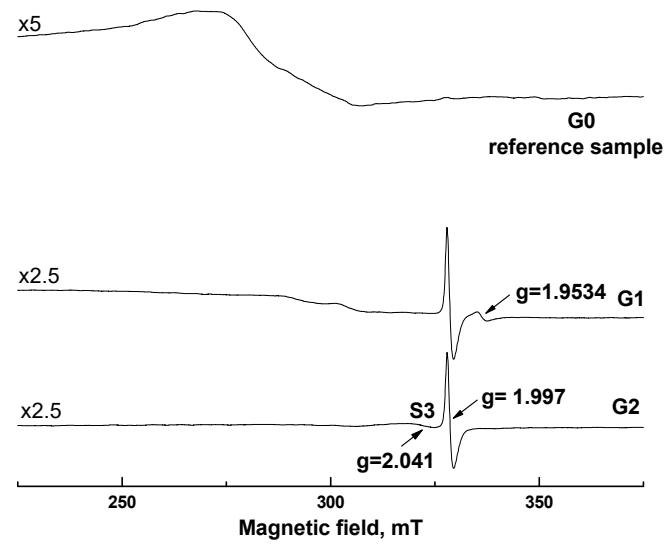

Figure 8. EPR spectra of plant-mediated $\mathrm{ZnO}$ powders.

Other researchers detected a similar peak with $g=2.003$, attributed to Zn vacancy [52] or nonaxial negatively charged Zn vacancy complexes [53]. In the spectrum of the G2 sample, the S1 signal disappeared, while a new resonance signal was detected at $322 \mathrm{mT}$ with $g=2.04$ (S3). Zhang et al. [51] observed a similar signal in N-implanted ZnO at $324 \mathrm{mT}$ 
$(\mathrm{g}=2.0025)$, which was attributed to $\mathrm{V}_{0}-\mathrm{V}_{Z \mathrm{Zn}}$ clusters. Other researchers recorded a signal at $\mathrm{g}=2.03$, associated with negatively charged zinc vacancy-interstitial zinc $\left(\mathrm{V}^{-} \mathrm{Zn}_{\mathrm{n}}: \mathrm{Zn}_{\mathrm{i}}{ }^{0}\right)$ complexes [53].

In order to investigate the type of atomic-scale defects in the samples, the PL spectra were measured at room temperature using a $325 \mathrm{~nm}$ excitation source. Figure 9 illustrates these results and as one can see, the spectra were very similar, with some intensity variations. More specifically, each spectrum exhibited a low-intensity UV near band-edge (NBE) emission at $375 \mathrm{~nm}$ and several intensive bands in the visible region. It is well known that the intensity ratio of the NBE to the defect-related visible emission could be taken as an indication of the crystalline quality of the sample [54]. As can be seen, the relatively strong intensity of the visible emission suggests a high degree of defect concentration in the samples. The latter observation is in agreement with the XRD results presented above (see Figure 1). The main peaks in the visible band were located at $425 \mathrm{~nm}, 514 \mathrm{~nm}$, and $607 \mathrm{~nm}$ and correspond to violet, green, and yellow emission, respectively. Based on previous studies, the prevailing violet emission can be attributed to the recombination of an electron in the defect state of zinc interstitials $\left(\mathrm{Zn}_{\mathrm{i}}\right)$ with a hole in the valence band [55]. The green band at $514 \mathrm{~nm}$ is correlated with the recombination of electrons in the ionized oxygen vacancies $\left(\mathrm{V}_{0}\right)$ with holes in the valence band [56]. The weak yellow emission $(607 \mathrm{~nm})$ seems to involve interstitial oxygen ions $\left(\mathrm{O}_{\mathrm{i}}{ }^{-}\right)$present on the surface of the samples [57]. Different origins of visible luminescence in $\mathrm{ZnO}$ nanostructures are fabricated by the chemical and evaporation methods.

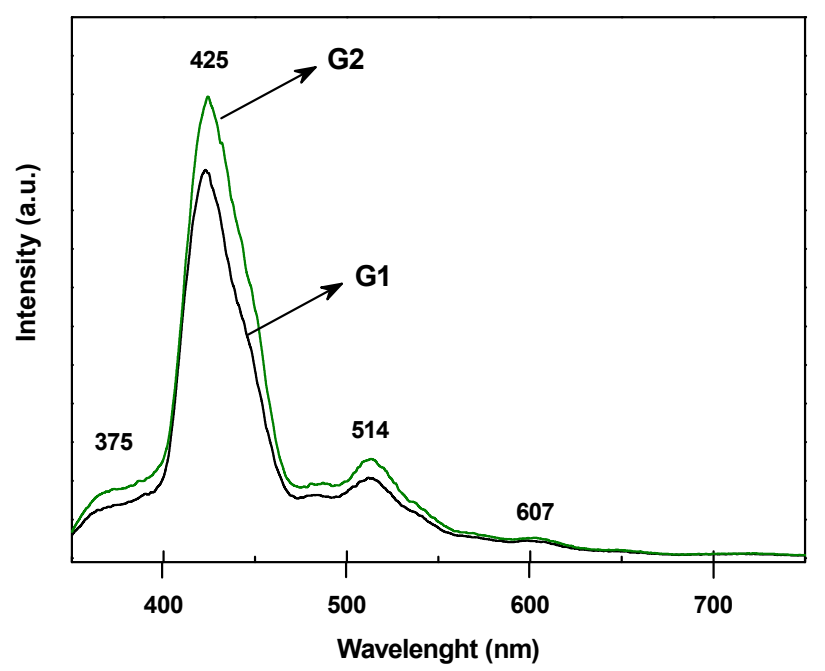

Figure 9. PL spectra of plant-mediated $\mathrm{ZnO}$ powders.

The XPS analysis showed that $\mathrm{C}, \mathrm{O}$, and $\mathrm{Zn}$ peaks were registered on the surface (Figure 10a).

The O1s peaks were deconvoluted by Lorentzian-Gaussian curve fitting into two components (Figure 10b). The first one at $\sim 530.2 \mathrm{eV}$ was assigned to lattice oxygen in $\mathrm{ZnO}$, and the second one at $\sim 532.2 \mathrm{eV}$ corresponded to hydroxyl groups adsorbed on the surface of the powders. 


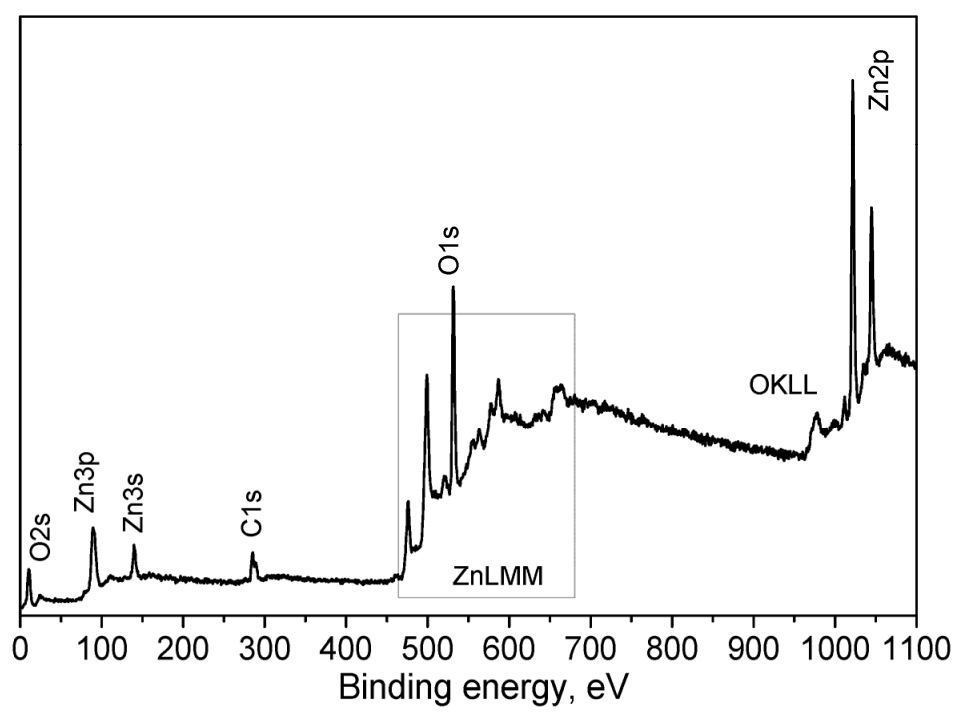

(a)

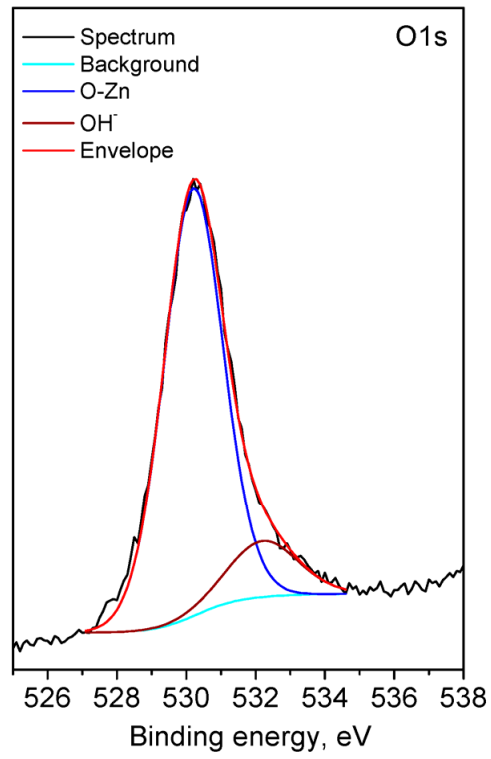

(b)

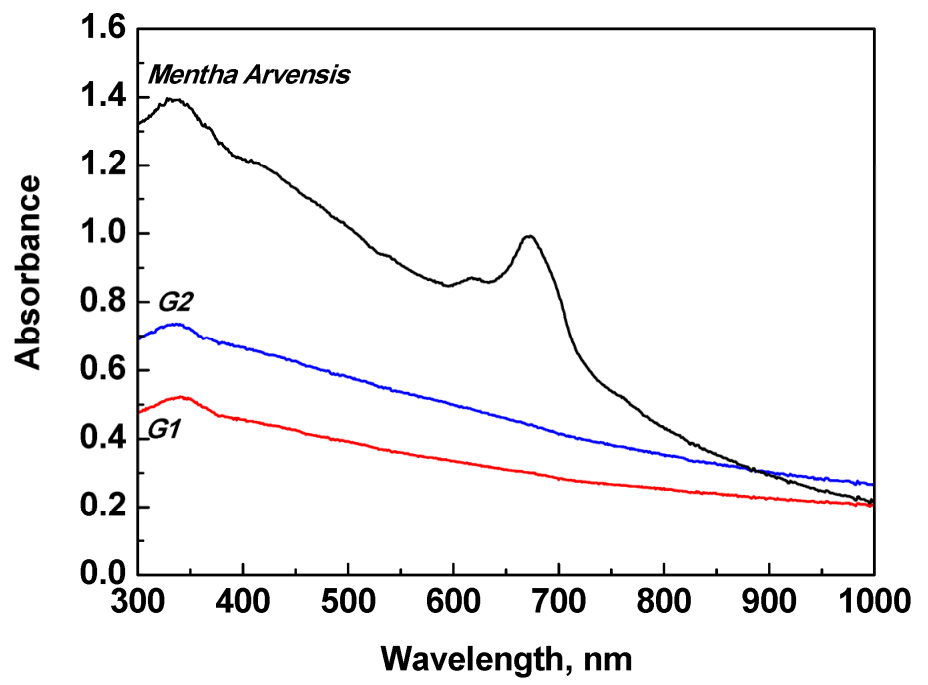

(c)

Figure 10. Cont. 


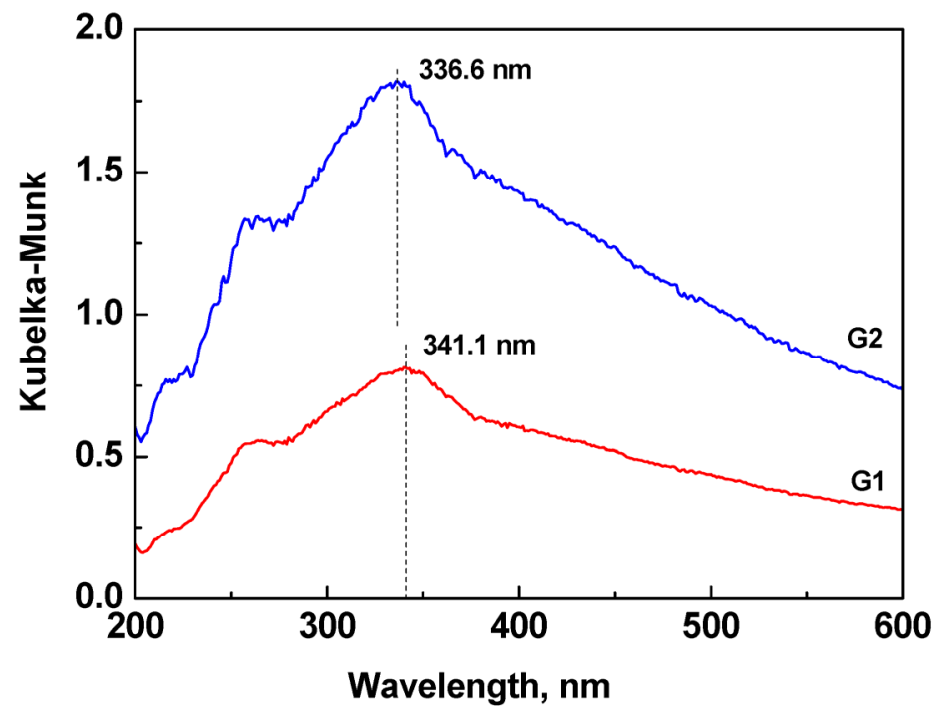

(d)

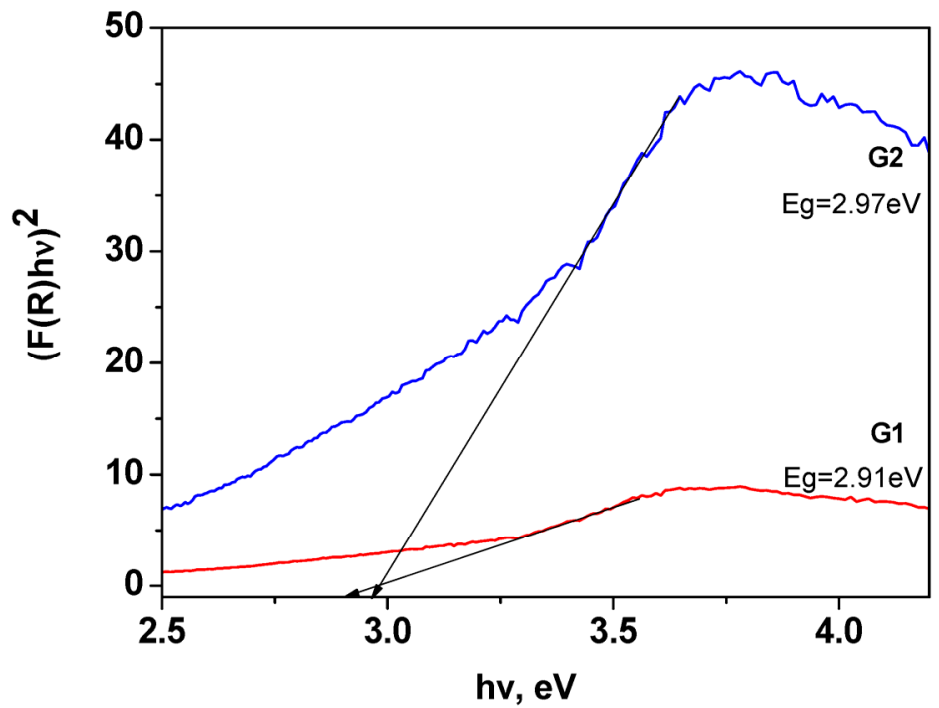

(e)

Figure 10. XPS spectrum of the photocatalyst: survey scan: (a) deconvoluted O1s peak, (b) absorbance spectrum, (c) absorbance spectrum with Kubelka-Munk transformation, (d) Tauk plot from UV-Vis analysis (e) of Mentha arvensis-mediated $\mathrm{ZnO}$ photocatalyst.

UV-vis diffuse-reflectance spectroscopy (DRS) was applied to determine the band gap energy $E_{g}$ of MA-mediated $\mathrm{ZnO}$ powders. The diffuse-reflectance spectra (DRS) were recorded on a Thermo Evolution 300 UV-VIS spectrometer, Waltham, Massachusetts, USA within the wavelength range of $190 \mathrm{~nm}$ to $1100 \mathrm{~nm}$. The changes in the form of the bands and in their relative intensity (caused by the mirrors) were taken into account by Kubelka-Munk transformation:

$$
F(R)=\frac{(1-R)^{2}}{2 R}=\frac{k}{s}
$$

where $\mathbf{R}$ is reflectance, $\mathbf{s}$ is the scattering coefficient, and $\mathbf{k}$ is the coefficient of molar absorbability [58]. The optical band gap was evaluated using the equation of Tauc:

$$
(\alpha h v)^{\frac{1}{n}}=A\left(h v-E_{g}\right)
$$


In Equation (2), $\boldsymbol{\alpha}$ is the coefficient of absorbance, $\mathbf{A}$ is a constant of proportionality, $\boldsymbol{h}$ is Planck's constant, and $v$ is the frequency of the photon. $\mathbf{E}_{\mathrm{g}}$ is the optical band gap, and in our case of direct transition, $\mathbf{n}$ equals $\mathbf{1} / \mathbf{2}$ [59]. The obtained DRS spectra acquire the form of the Kubelka-Munch's function and therefore the Tauk equation becomes:

$$
(h v F(R \infty))^{\frac{1}{n}}=A\left(h v-E_{g}\right)
$$

The extrapolation of the linear section of the graph $(\mathrm{h} v \mathrm{~F}(\mathrm{R} \infty))^{1 / \mathrm{n}}$ from $\mathrm{h} v$ gives the value of the optical width of the energy band gap. The UV-vis absorption spectra of the $\mathrm{ZnO}$ powders showed absorption peaks at $336.6 \mathrm{~nm}$ for G2 and $341.1 \mathrm{~nm}$ for G1 (Figure 10c-e). Figure 10e represents Tauc's types of plots and estimated band gap values. The band gap of the reference $\mathrm{ZnO}$ powder was $3.24 \mathrm{eV}$, while the biosynthesized powders had lower band gap values (2.97 and $2.91 \mathrm{eV}$ for G1 and G2, respectively). This fact is explained by the substitution of some plant chemicals into the $\mathrm{ZnO}$ lattice sites [60] or by the presence of defects in the $\mathrm{ZnO}$ lattice, which are situated below the conduction band [61].

The photocatalytic properties of the samples were investigated in the reaction of the photocatalytic discoloration of Malachite Green dye as a model contaminant in aqueous solutions (Figure 11a). The values of the calculated pseudo-first-order kinetic apparent rate constants increased in the following order: G0 sample $\left(\mathrm{k}_{0}=4.4 \times 10^{-3} \mathrm{~min}^{-1}\right)<\mathrm{G} 1$ $\left(\mathrm{k}_{2}=5.4 \times 10^{-3} \mathrm{~min}^{-1}\right)<\mathrm{G} 2\left(\mathrm{k}_{2}=11.8 \times 10^{-3} \mathrm{~min}^{-1}\right)$ for $120 \mathrm{~min}$ of UV irradiation. The highest degree of discoloration of the model contaminant dye (74\%) was achieved in the presence of the G2 photocatalyst. The samples G0 and G1 exhibited lower discoloration values: $45 \%$ and $41 \%$, respectively.

The performed three consecutive photocatalytic activity tests showed that the discoloration degree of the model dye decreased very slightly from the first until the third cycle in the presence of G2 and consequently maintained the photocatalytic efficiency relatively well. The tests are demonstration of the stability of the MA-mediated $\mathrm{ZnO}$ powders (Figure 11b). It is well known that the UV light irradiation cause photogeneration of electrical charges, which occurs inside biosynthesized ZnO. (Figure 11c). The first stage is adsorption of the model dye. In our case, it could be supposed that $\pi-\pi$ interactions with the aromatic rings belonging to the plant extract occur. The redox reactions on the oxide surface produce effective oxidizing agents such as hydroxyl free radicals $\left(\mathrm{OH}^{-}\right)$and superoxide ions $\left(\mathrm{O}_{2}{ }^{-}\right)$, which play important roles in the photocatalytic discoloration of the model dye. According to the research work of [62], the photodegradation of MG dye occurs through three reactions: N-demethylation, decomposition of the benzene structure, and cleavage of the conjugated structure. It is known that the dye color is due to delocalization of $\pi$ electrons of the benzene ring. Photoexcitation causes jumping of $\pi$-electrons from the valence band over the band gap to the conduction band, and the delocalization is disrupted. The final stage is mineralization of the organic pollutant [63]. The hydrothermal synthesis enables preparation of low-aggregated zinc oxide particles under mild conditions and easy control of technological parameters. Our previous experiments on $\mathrm{ZnO}$ particle synthesis involved the use of urea as a precipitating agent in view of the highest photocatalytic efficiency in the oxidative dye degradation. The use of urea as a precipitating agent ensured homogeneous precipitation, while $\mathrm{NaOH}$ led to faster precipitation and a lower surface area. The samples obtained using urea had a higher specific surface area and greater share of mesopores. Only a few studies have reported the preparation of $\mathrm{ZnO}$ by hydrothermal treatment of a precipitate, obtained using a plant extract [64]. In the present study, we used the advantages of both: the hydrothermal synthesis and the application of a plant extract as a stabilizing/reducing agent. As a result, highly effective $\mathrm{ZnO}$ photocatalysts with a high specific surface area (80-140 $\mathrm{m}^{2} / \mathrm{g}$ ) and larger share of mesopores (pore sizes: 16$17 \mathrm{~nm}$ ) were obtained. The higher surface area and pore size ensure better charge diffusion, mass transportation, and a faster reaction rate of discoloration. On the contrary, common green synthesis (with conventional precipitant $\mathrm{NaOH}$ ) without hydrothermal activation leads to the preparation of particles with a lower specific surface area and smaller pore 
sizes [65]. The method proposed by us involves three stages: precipitation by means of the Mentha arvensis extract, hydrothermal treatment, and a final low-temperature treatment to effectively control the texture and morphology, thus ensuring the successful preparation of highly active photocatalysts. Our experimental results have proved that the Mentha arvensismediated $\mathrm{ZnO}$ powders exhibit increased photocatalytic efficiency for UV-light irradiation, causing discoloration of the model dye in comparison to that obtained by a non-modified approach. Both the EPR and PL studies have proved convincingly the presence of $\mathrm{Zn}_{\mathrm{i}}$ and $\mathrm{V}_{0}$ defects. It is likely that $\mathrm{ZnO}$ is modified by nitrogen, originating from the precipitant. It was revealed that the $\mathrm{N}$ ion implantation can induce a large number of $\mathrm{V}_{\mathrm{Zn}}$ and $\mathrm{V}_{0}$ defects [51]. Pei and co-workers [66] reported that the presence of both $\mathrm{Zn}_{\mathrm{i}}$ and $\mathrm{V}_{0}$ in $\mathrm{ZnO}$ is beneficial for achieving good transportation and separation of photo-excited charge carriers, thus causing the improvement of the $\mathrm{ZnO}$ photocatalytic performance. Hence, our PL and EPR results suggest that the as-prepared samples could be promising candidates for efficient photocatalysts. In addition to the presence of the defects in $\mathrm{ZnO}$, the degree of crystallinity favorably influences the rate of the photocatalytic process. There is great disagreement between studies concerning the role of this structure parameter in the dye photodegradation. The multiple data have revealed that highly crystalline materials are efficient photocatalysts [67], but some researchers have reported that the amorphous or poorly crystallized structure could promote the photocatalytic properties [68,69]. In our case, the best photocatalyst G2 (it exhibited the highest photocatalytic discoloration rate) had a two-phase crystalline structure: poorly crystallized wurtzite and almost amorphous hydrozincite. Guo et al. [70] also revealed that the combination of crystalline and amorphous phases in $\mathrm{ZnO} / \mathrm{TiO}_{2}$ ensured a larger number of active sites, originating from the lattice defects. In addition, the presence of two or more crystalline phases also favors the photocatalytic performance due to the presence of numerous interphase defects. A similar effect was observed for nanoparticles, consisting of mixed $\mathrm{TiO}_{2}$ phases [71-74]. The morphological (particle shape and size) and textural (specific surface area, pore sizes) features are also responsible for the better electron-hole diffusion, mass transportation, and improved activity of the plant-mediated $\mathrm{ZnO}$ powders. The use of the plant extract leads to a decrease in the crystallite size (proved by the XRD), which is responsible for the higher specific area. Other researchers have also proved that the enhanced photocatalytic ability of $\mathrm{ZnO}$ NPs, prepared via Hibiscus sabdariffa extract, is favored by the smaller crystallite size [75]. The plant extract yields plate-like morphology and well-defined mesoporous structure with the greatest share of mesopores in comparison with the reference sample. The larger number of mesopores ensures more active sites and facilitates the diffusion of large reactant molecules [74]. Microscopic observations have confirmed that application of MA leads to more effective particle separation, probably due to the presence of long-chain phytochemicals [76].

The results obtained in the present study have proved the positive role of MA extract as a reducing/capping agent in the control over all of the above-mentioned factors, responsible for the increased photocatalytic efficiency of plant-mediated $\mathrm{ZnO}$ powders. We hope that the newly obtained zinc-containing composite material, possessing a bi-phase structure, can find applications not only in the field of photocatalytic processes, but also in some other fields of solid-state materials chemistry. 


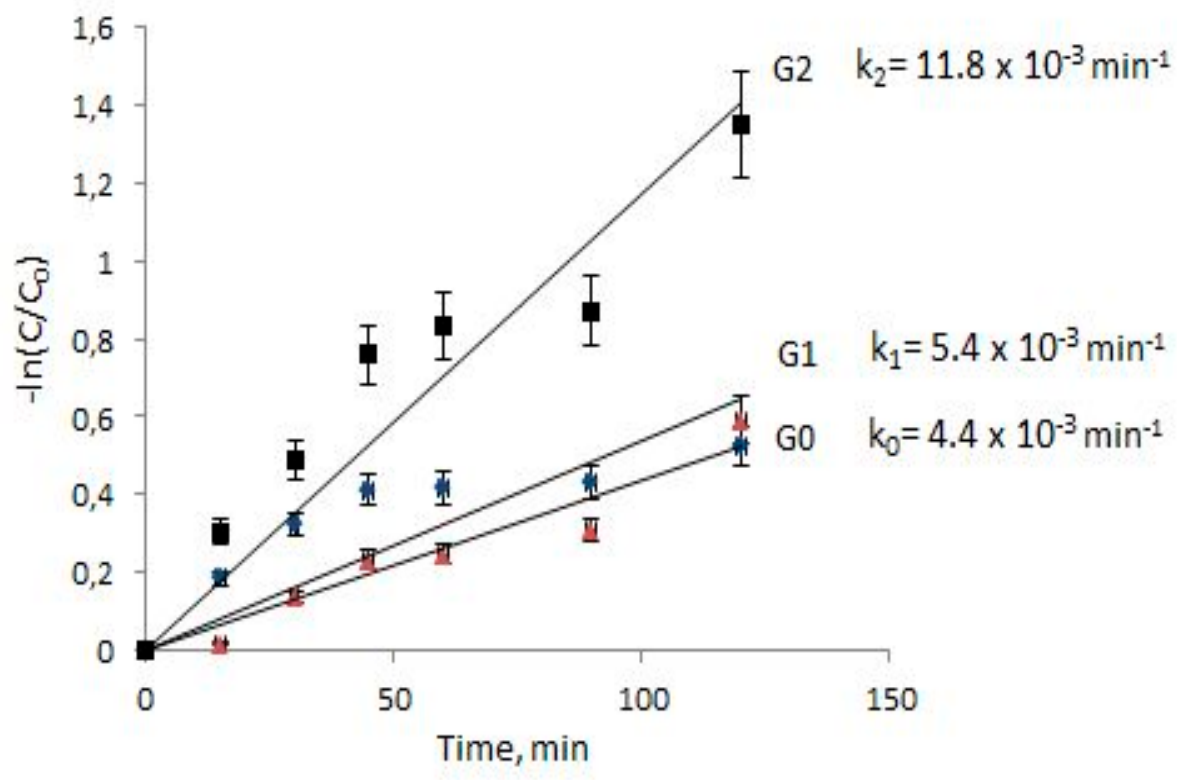

(a)

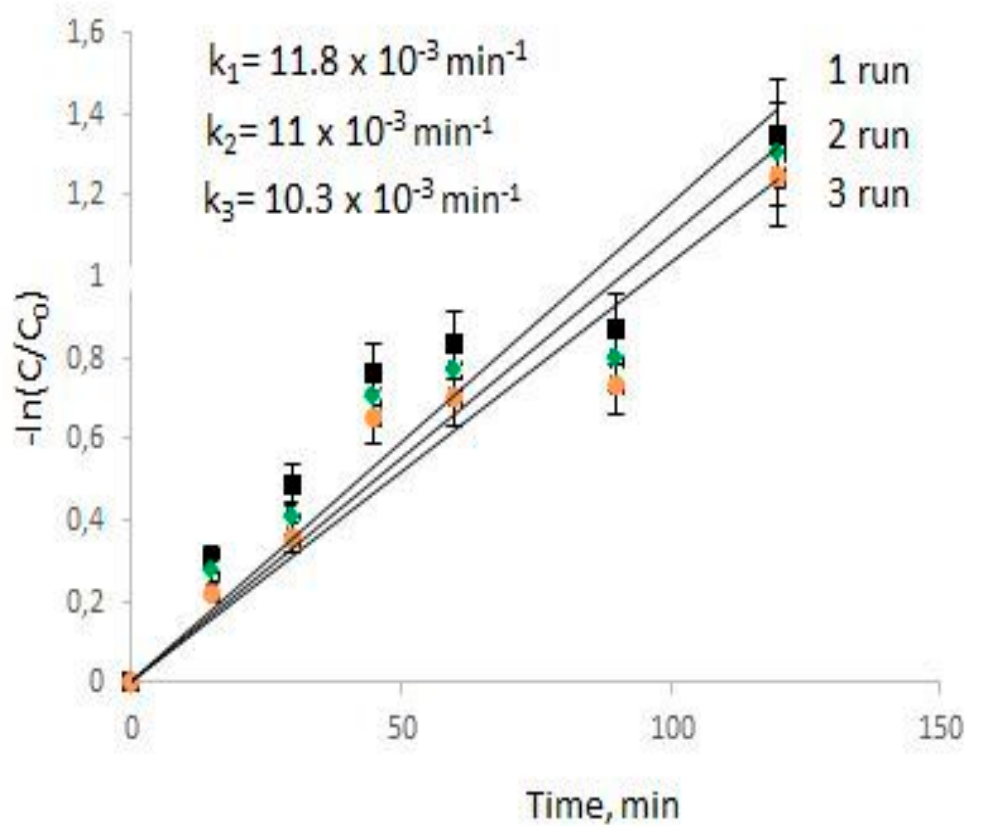

(b)

Figure 11. Cont. 


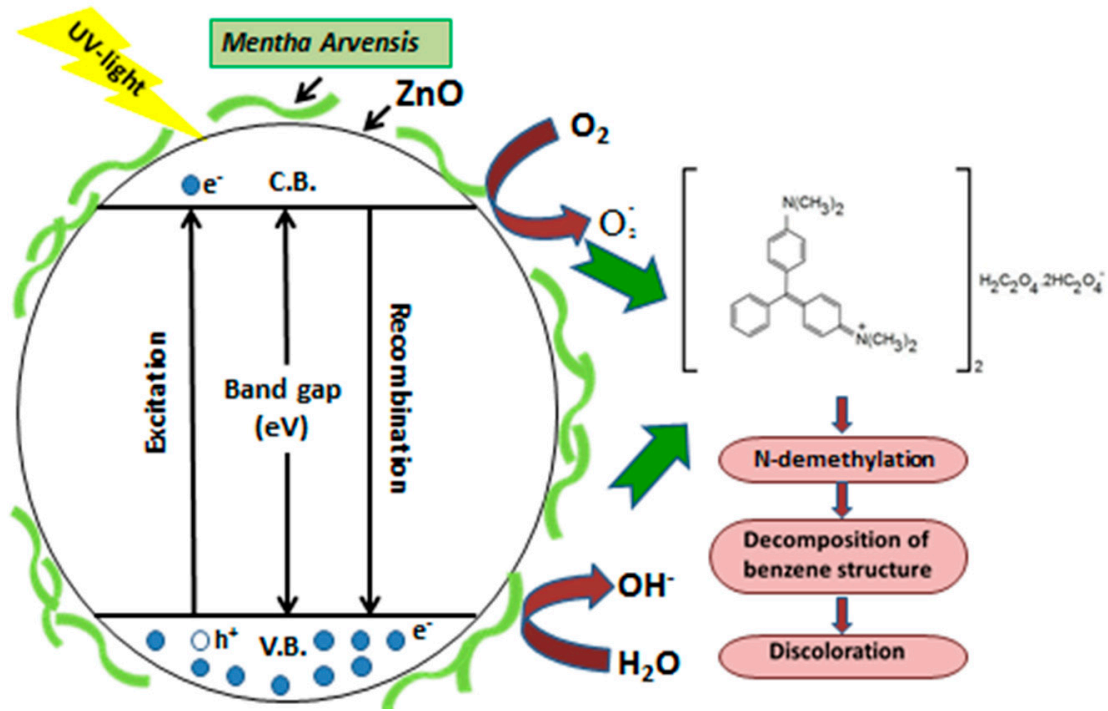

(c)

Figure 11. Kinetic curves of UV-discoloration of Malachite Green dye using G0, G1, and G2 photocatalysts (a); Kinetic curves of UV-discoloration using the G2 photocatalyst after three consecutive photocatalytic cycles (b); Probable mechanism of the UV-induced discoloration of the MG dye using Mentha arvensis-mediated $\mathrm{ZnO}$ (c).

\section{Conclusions}

It has been established that the application of MA extract in the bio-hydrothermal synthesis of $\mathrm{ZnO}$ particles induced a series of beneficial physicochemical effects: decrease in the crystallite size, increased share of mesopores, formation of a two-phase (hydrozincite and wurtzite) crystalline structure, smaller band gap value, and formation of lattice defects $\left(\mathrm{Zn}_{\mathrm{i}}\right.$ and $\left.\mathrm{V}_{0}\right)$. All of these effects determined the improved photocatalytic efficiency for discoloration of Malachite Green dye under UV light.

The best Mentha arvensis-modified $\mathrm{ZnO}$ sample exhibited a 74\% discoloration degree of the Malachite Green model contaminant dye for 120 min under UV light. The reusability, monitored in three consecutive tests, proved the stability of the best MA-mediated $\mathrm{ZnO}$. The applied simple and non-toxic approach for the preparation of stable and effective $\mathrm{ZnO}$ powders enables possibilities for a wide scope of applications.

In addition, the green-synthesized particles with modified structure and morphological features could be used for the preparation of a zinc precursor solution for obtaining $\mathrm{ZnO}$ nanoparticles or $\mathrm{ZnO}$-based nanocontainers with an inhibitor serving as an effective anticorrosion layer on steel. The dependence between the plant extract content and the physicochemical features of the green synthesized particles can be used as a means for the fine tuning of their final properties. This would allow us to widen the practical application of $\mathrm{ZnO}$ not only as a photocatalyst but also in other areas related to the protection of the environment, human health, and enhanced corrosion resistance of different industrial and civil structures.

Author Contributions: Conceptualization, D.S., I.S. and V.B.; methodology, D.S., I.S., P.G., K.Z. and V.B.; formal analysis M.S., R.M., O.D., P.M., V.D., Y.K., G.T., investigation M.S., R.M., O.D., P.M., V.D., Y.K., G.T., K.Z.; writing—original draft preparation; writing—review and editing: D.S., I.S., N.B. (Nelly Boshkova), N.B. (Nikolai Boshkov) and V.B.; visualization.; R.M., O.D., P.M., G.T., K.Z., D.S. and I.S. All authors have read and agreed to the published version of the manuscript.

Funding: National Science Fund, Bulgaria, KP-06-N37/16 (KП-06-H37/16) “New environmentally friendly one- and multi-layer coatings for corrosion protection of structural materials with wide application". 
Acknowledgments: The authors express their gratitude for the Project with the National Science Fund, Bulgaria, KP-06-N37/16 (KП-06-H37/16) "New environmentally friendly one- and multi-layer coatings for corrosion protection of structural materials with wide application" for the financial support to realize these investigations.

Conflicts of Interest: The authors declare no conflict of interest.

\section{References}

1. Klingshirn, C. ZnO: From basics towards applications. Phys. Status Solidi B 2007, 244, 3027-3073. [CrossRef]

2. Djurišić, A.; Ng, A.M.C.; Chen, X. ZnO nanostructures for optoelectronics: Material properties and device applications. Prog. Quantum Electron. 2010, 34, 191-259. [CrossRef]

3. Bu, D.; Batmunkh, M.; Zhang, Y.; Li, Y.; Qian, B.; Lan, Y.; Hou, X.; Li, S.; Jia, B.; Song, X.-M.; et al. Rechargeable sunlight-promoted $\mathrm{Zn}$-air battery constructed by bifunctional oxygen photoelectrodes: Energy-band switching between $\mathrm{ZnO} / \mathrm{Cu}{ }_{2} \mathrm{O}$ and $\mathrm{ZnO} / \mathrm{CuO}$ in charge-discharge cycles. Chem. Eng. J. 2021, 133559. [CrossRef]

4. Xiang, D.; Liu, Z.; Wu, M.; Liu, H.; Zhang, X.; Wang, Z.; Wang, Z.L.; Li, L. Enhanced Piezo-Photoelectric Catalysis with Oriented Carrier Migration in Asymmetric Au-ZnO Nanorod Array. Small 2020, 16, e1907603. [CrossRef]

5. Gao, G.; Yu, L.; Vinu, A.; Shapter, J.G.; Batmunkh, M.; Shearer, C.J.; Yin, T.; Huang, P.; Cui, D. Synthesis of ultra-long hierarchical $\mathrm{ZnO}$ whiskers in a hydrothermal system for dye-sensitised solar cells. RSC Adv. 2016, 6, 109406-109413. [CrossRef]

6. Laurent, S.; Boutry, S.; Muller, R. Chapter 1-Metal Oxide Particles and Their Prospects for Applications. In Iron Oxide Nanoparticles for Biomedical Applications; Elsevier: Amsterdam, The Netherlands, 2018; pp. 3-42. [CrossRef]

7. Samad, U.A.; Alam, M.A.; Anis, A.; Sherif, E.M.; Al-Mayman, S.I.; Al-Zahrani, S.M. Effect of Incorporated ZnO Nanoparticles on the Corrosion Performance of $\mathrm{SiO}_{2}$ Nanoparticle-Based Mechanically Robust Epoxy Coatings. Materials 2020, 13, 3767. [CrossRef]

8. Sharma, D.K.; Shukla, S.; Sharma, K.K.; Kumar, V. A review on ZnO: Fundamental properties and applications. Mater. Today Proc. 2020, 49, 3028-3035. [CrossRef]

9. Srivastava, V.; Gusain, D.; Sharma, Y.C. Synthesis, characterization and application of zinc oxide nanoparticles (n-ZnO). Ceram. Int. 2013, 39, 9803-9808. [CrossRef]

10. Chavali, M.S.; Nikolova, M.P. Metal oxide nanoparticles and their applications in nanotechnology. SN Appl. Sci. $2019,1,607$. [CrossRef]

11. Karbowniczek, J.; Cordero-Arias, L.; Virtanen, S.; Misra, S.K.; Valsami-Jones, E.; Tuchscherr, L.; Rutkowski, B.; Górecki, K.; Bała, P.; Czyrska-Filemonowicz, A.; et al. Electrophoretic deposition of organic/inorganic composite coatings containing ZnO nanoparticles exhibiting antibacterial properties. Mater. Sci. Eng. C 2017, 77, 780-789. [CrossRef]

12. Cordero-Arias, L.; Cabanas-Polo, S.; Goudouri, O.; Misra, S.; Gilabert, J.; Valsami-Jones, E.; Sanchez, E.; Virtanen, S.; Boccaccini, A. Electrophoretic deposition of $\mathrm{ZnO} /$ alginate and $\mathrm{ZnO}$-bioactive glass/alginate composite coatings for antimicrobial applications. Mater. Sci. Eng. C 2015, 55, 137-144. [CrossRef] [PubMed]

13. Penchev, H.; Zaharieva, K.; Milenova, K.; Ublekov, F.; Dimova, S.; Budurova, D.; Staneva, M.; Stambolova, I.; Sinigersky, V.; Blaskov, V. Novel meta- and AB-Polybenzimidazole/Zinc oxide polymer hybrid nanomaterials for photocatalytic degradation of organic dyes. Mater. Lett. 2018, 230, 187-190. [CrossRef]

14. Dimova, S.; Zaharieva, K.; Ublekov, F.; Kyulavska, M.; Stambolova, I.; Blaskov, V.; Nihtianova, D.; Markov, P.; Penchev, H. Novel dye degradation photocatalyst nanocomposite powders based on polydiphenylacetylene-zinc oxide in polystyrene matrix. Mat. Lett. 2020, 269, 127683. [CrossRef]

15. Kamburova, K.; Boshkova, N.; Radeva, T. Composite coatings with polymeric modified ZnO nanoparticles and nanocontainers with inhibitor for corrosion protection of low carbon steel. Colloids Surf. A Physicochem. Eng. Asp. 2020, 609, 125741. [CrossRef]

16. McCluskey, M.; Jokela, S.J. Defects in ZnO. J. Appl. Phys. 2009, 106, 071101. [CrossRef]

17. Stambolova, I.; Blaskov, V.; Stoyanova, D.; Avramova, I.; Dimitrov, L.; Milenova, K.; Balashev, K.; Simeonova, S.; Tzonev, A.; Aleksandrov, L.; et al. Dependence of the textural properties and surface species of $\mathrm{ZnO}$ photocatalytic materials on the type of precipitating agent used in the hydrothermal synthesis. Bull. Mater. Sci. 2017, 40, 483-492. [CrossRef]

18. Ibhadon, A.O.; Fitzpatrick, P. Heterogeneous Photocatalysis: Recent Advances and Applications. Catalysts 2013, 3, 189-218. [CrossRef]

19. Wang, H.; Xie, C.; Zhang, W.; Cai, S.; Yang, Z.; Gui, Y. Comparison of dye degradation efficiency using ZnO powders with various size scales. J. Hazard. Mater. 2007, 141, 645-652. [CrossRef] [PubMed]

20. Wang, S.L.; Zhu, H.W.; Tang, W.; Li, P.G. Propeller-Shaped ZnO Nanostructures Obtained by Chemical Vapor Deposition: Photoluminescence and Photocatalytic Properties. J. Nanomater. 2012, 2012, 594290. [CrossRef]

21. Zhou, Z.; Wang, J.; Jhun, C. ZnO Nanospheres Fabricated by Mechanochemical Method with Photocatalytic Properties. Catalysts 2021, 11, 572. [CrossRef]

22. Shen, W.; Li, Z.; Wang, H.; Liu, Y.; Guo, Q.; Zhang, Y. Photocatalytic degradation for methylene blue using zinc oxide prepared by codeposition and sol-gel methods. J. Hazard. Mater. 2008, 152, 172-175. [CrossRef]

23. Lee, Y.; Fujimoto, T.; Yamanaka, S.; Kuga, Y. Evaluation of photocatalysis of Au supported ZnO prepared by the spray pyrolysis method. Adv. Powder Technol. 2021, 32, 1619-1626. [CrossRef] 
24. Sansenya, T.; Masri, N.; Chankhanittha, T.; Senasu, T.; Piriyanon, J.; Mukdasai, S.; Nanan, S. Hydrothermal synthesis of ZnO photocatalyst for detoxification of anionic azo dyes and antibiotic. J. Phys. Chem. Solids 2021, 160, 110353. [CrossRef]

25. Blaskov, V.; Stambolova, I.; Dimitrov, L.; Shipochka, M.; Stoyanova, D.; Eliyas, A. Nanosized $\mathrm{Zn}_{2} \mathrm{SnO}_{4}$ powders synthesized by coprecipitation and consecutive hydrothermal treatment in two different alkaline media. Bulg. Chem. Commun. 2017, 50, 58-62.

26. Basnet, P.; Chatterjee, S. Structure-directing property and growth mechanism induced by capping agents in nanostructured ZnO during hydrothermal synthesis-A systematic review. Nano-Struct. Nano-Objects 2020, 22, 100426. [CrossRef]

27. Huang, Y.; Haw, C.Y.; Zheng, Z.; Kang, J.; Zheng, J.; Wang, H. Biosynthesis of Zinc Oxide Nanomaterials from Plant Extracts and Future Green Prospects: A Topical Review. Adv. Sustain. Syst. 2021, 5, 2000266. [CrossRef]

28. Fagier, M.A. Plant-Mediated Biosynthesis and Photocatalysis Activities of Zinc Oxide Nanoparticles: A Prospect towards Dyes Mineralization. J. Nanotechnol. 2021, 2021, 6629180. [CrossRef]

29. Hassan, S.S.M.; Azab, W.I.M.E.; Ali, H.R.; Mansour, M. Green synthesis and characterization of ZnO nanoparticles for photocatalytic degradation of anthracene. Adv. Nat. Sci. Nanosci. Nanotechnol. 2015, 6, 045012. [CrossRef]

30. Aminuzzaman, M.; Ying, L.P.; Goh, W.-S.; Watanabe, A. Green synthesis of zinc oxide nanoparticles using aqueous extract of Garcinia mangostana fruit pericarp and their photocatalytic activity. Bull. Mater. Sci. 2018, 41, 50. [CrossRef]

31. Chauhan, A.; Verma, R.; Kumari, S.; Sharma, A.; Shandilya, P.; Li, X.; Batoo, K.M.; Imran, A.; Kulshrestha, S.; Kumar, R. Photocatalytic dye degradation and antimicrobial activities of Pure and Ag-doped ZnO using Cannabis sativa leaf extract. Sci. Rep. 2020, 10, 7881. [CrossRef]

32. Osuntokun, J.; Onwudiwe, D.C.; Ebenso, E.E. Green synthesis of ZnO nanoparticles using aqueous Brassica oleracea L. var. italica and the photocatalytic activity. Green Chem. Lett. Rev. 2019, 12, 444-457. [CrossRef]

33. Suresh, D.; Nethravathi, P.C.; Udayabhanu; Rajanaika, H.; Bhushana, N.; Sharma, S. Green synthesis of multifunctional zinc oxide $(\mathrm{ZnO})$ nanoparticles using Cassia fistula plant extract and their photodegradative, antioxidant and antibacterial activities. Mater. Sci. Semicond. Process. 2015, 31, 446-454. [CrossRef]

34. Abdelkhalek, A.; Al-Askar, A.A. Green Synthesized ZnO Nanoparticles Mediated by Mentha Spicata Extract Induce Plant Systemic Resistance against Tobacco Mosaic Virus. Appl. Sci. 2020, 10, 5054. [CrossRef]

35. Rad, S.S.; Sani, A.M.; Mohseni, S. Biosynthesis, characterization and antimicrobial activities of zinc oxide nanoparticles from leaf extract of Mentha pulegium (L.). Microb. Pathog. 2019, 131, 239-245. [CrossRef]

36. Ahmad, W.; Kumar, K.; Soni, S. Green synthesis if titanium dioxide $\left(\mathrm{TiO}_{2}\right)$ nanoparticles by using Mentha Arvenis leafs extract and its antimicrobial properties. Inorg. Nanometal. Chem. 2020, 50, 1032-1038. [CrossRef]

37. Babu, P.J.; Sharma, P.; Borthakur, B.B.; Das, R.K.; Nahar, P.; Bora, U. Synthesis of Gold Nanoparticles Using Mentha arvensis Leaf Extract. Int. J. Green Nanotechnol. Biomed. 2010, 2, 62-68. [CrossRef]

38. Manjula, R.; Prasad, B.D.; Vidya, Y.; Nagabhushana, H.; Anantharaju, K. Mentha Arvensis mediated synthesis and characterization of zinc oxide nanoparticles for energy applications. Mater. Today Proc. 2021, 46, 6051-6055. [CrossRef]

39. Mohammadi, F.M.; Ghasemi, N. Influence of temperature and concentration on biosynthesis and characterization of zinc oxide nanoparticles using cherry extract. J. Nanostruct. Chem. 2018, 8, 93-102. [CrossRef]

40. Elumalai, K.; Velmurugan, S.; Ravi, S.; Kathiravan, V.; Raj, G.A. Bio-approach: Plant mediated synthesis of ZnO nanoparticles and their catalytic reduction of methylene blue and antimicrobial activity. Adv. Powder Technol. 2015, 26, 1639-1651. [CrossRef]

41. Kraus, W.; Nolze, G. Powder Cell for Windows, Federal Institute for Materials Research and Testing; International Union of Crystallography: Berlin, Germany, 2000.

42. Williamson, G.K.; Hall, W.H. X-ray line broadening from filed aluminium and wolfram. Acta Metall. 1953, 1, 22-31. [CrossRef]

43. Demissie, M.G.; Sabir, F.K.; Edossa, G.D.; Gonfa, B.A. Synthesis of Zinc Oxide Nanoparticles Using Leaf Extract of Lippia adoensis (Koseret) and Evaluation of Its Antibacterial Activity. J. Chem. 2020, 2020, 7459042. [CrossRef]

44. Mohammadi-Aloucheh, R.; Habibi-Yangjeh, A.; Bayrami, A.; Latifi-Navid, S.; Asadi, A. Green synthesis of ZnO and ZnO/CuO nanocomposites in Mentha longifolia leaf extract: Characterization and their application as anti-bacterial agents. J. Mater. Sci. Mater. Electron. 2018, 29, 13596-13605. [CrossRef]

45. Gawade, V.V.; Gavade, N.L.; Shinde, H.M.; Babar, S.B.; Kadam, A.; Garadkar, K.M. Green synthesis of ZnO nanoparticles by using Calotropis procera leaves for the photodegradation of methyl orange. J. Mater. Sci. Mater. Electron. 2017, 28, 14033-14039. [CrossRef]

46. Pramila, D.M.; Xavier, R.; Marimuthu, K.; Kathiresan, S.; Khoo, M.L.; Senthilkumar, M.; Sathya, K.; Sreeramanan, S. Phytochemical analysis and antimicrobial potential of methanolic leaf extract of peppermint (Mentha piperita: Lamiaceae). J. Med. Plants Res. 2012, 6, 331-335. [CrossRef]

47. Music, S.; Popović, S.; Maljković, M.; Dragčević, D. Influence of synthesis procedure on the formation and properties of zinc oxide. J. Alloys Compd. 2002, 347, 324-332. [CrossRef]

48. Liewhiran, C.; Seraphin, S.; Phanichphant, S. Synthesis of nano-sized ZnO powders by thermal decomposition of zinc acetate using Broussonetia papyrifera (L.) Vent pulp as a dispersant. Curr. Appl. Phys. 2006, 6, 499-502. [CrossRef]

49. Jakes, P.; Erdem, E. Finite size effects in ZnO nanoparticles: An electron paramagnetic resonance (EPR) analysis. Phys. Status solidi (RRL) Rapid Res. Lett. 2011, 5, 56-58. [CrossRef]

50. Krasil'nikov, V.; Dyachkova, T.; Tyutyunnik, A.; Gyrdasova, O.; Melkozerova, M.; Baklanova, I.; Perevozchikova, Y.A.; Emelyanova, S.; Weber, H.; Marchenkov, V. Magnetic and optical properties as well as EPR studies of polycrystalline ZnO synthesized from different precursors. Mater. Res. Bull. 2017, 97, 553-559. [CrossRef] 
51. Li, W.; Zhang, H.; Zhang, X.; Qin, G.; Li, H.; Xiong, Y.; Ye, L.; Ruan, H.; Tong, C.; Kong, C.; et al. Non-axial NO-VZn shallow acceptor complexes in nitrogen implanted p-type ZnO thin films. Appl. Surf. Sci. 2020, 529, 147168. [CrossRef]

52. Smith, J.; Vehse, W. ESR of electron irradiated ZnO confirmation of the F+ center. Phys. Lett. A 1970, 31, 147-148. [CrossRef]

53. Stan, M.; Popa, A.; Toloman, D.; Dehelean, A.; Lung, I.; Katona, G. Enhanced photocatalytic degradation properties of zinc oxide nanoparticles synthesized by using plant extracts. Mater. Sci. Semicond. Process. 2015, 39, 23-29. [CrossRef]

54. Bazta, O.; Urbieta, A.; Piqueras, J.; Fernández, P.; Addou, M.; Calvino, J.; Hungría, A. Influence of yttrium doping on the structural, morphological and optical properties of nanostructured $\mathrm{ZnO}$ thin films grown by spray pyrolysis. Ceram. Int. 2018, 45, 6842-6852. [CrossRef]

55. Rainey, K.; Chess, J.; Eixenberger, J.; Tenne, D.A.; Hanna, C.B.; Punnoose, A. Defect induced ferromagnetism in undoped ZnO nanoparticles. J. Appl. Phys. 2014, 115, 17D727. [CrossRef]

56. Chiang, Y.-F.; Kuo, S.; Liu, C.; Huang, J.; Yao, W.; Wu, Y. Tuning of crystal quality and optical properties of hydrothermally synthesized $\mathrm{ZnO}$ nanorods by magnetic field. Mater. Chem. Phys. 2014, 148, 1113-1118. [CrossRef]

57. Li, D.; Leung, Y.H.; Djurišić, A.B.; Liu, Z.T.; Xie, M.H.; Shi, S.L.; Xu, S.; Chan, W.K. Different origins of visible luminescence in $\mathrm{ZnO}$ nanostructures fabricated by the chemical and evaporation methods. Appl. Phys. Lett. 2004, 85, 1601-1603. [CrossRef]

58. Hanrahan, P.; Krueger, W. Reflection from layered surfaces due to subsurface scattering. In Proceedings of the 20th Annual Conference on Computer Graphics and Interactive Techniques, Anaheim, CA, USA, 2-6 August 1993; pp. 165-174.

59. Suwanboon, S. Structural and Optical Properties of Nanocrystalline ZnO Powder from Sol-Gel Method. Sci. Asia 2008, 34, 031-034. [CrossRef]

60. Fu, L.; Fu, Z. Plectranthus amboinicus leaf extract-assisted biosynthesis of $\mathrm{ZnO}$ nanoparticles and their photocatalytic activity. Ceram. Int. 2015, 41, 2492-2496. [CrossRef]

61. Alharthi, M.; Ismail, I.; Bellucci, S.; Khdary, N.; Salam, M.A. Biosynthesis Microwave-Assisted of Zinc Oxide Nanoparticles with Ziziphus jujuba Leaves Extract: Characterization and Photocatalytic Application. Nanomaterials 2021, 11, 1682. [CrossRef]

62. Perez-Estrada, L.A.; Aguera, A.; Hernando, M.D.; Malato, S.; Fernnandez-Alba, A.R. Photodegradation of malachite green under natural sunlight irradiation: Kinetic and toxicity of the transformation products. Chemosphere 2008, 70, 2068-2075. [CrossRef] [PubMed]

63. Gao, G.; Zhang, A.; Zhang, M.; Chen, J.; Zhang, Q. Photocatalytic Degradation Mechanism of Malachite Green under Visible Light Irradiation over Novel Biomimetic Photocatalyst HMS-FePcs. Chin. J. Catal. 2008, 29, 426-430. [CrossRef]

64. Zare, M.; Namratha, K.; Alghamdi, S.; Mohammad, Y.H.E.; Hezam, A.; Zare, M.; Drmosh, Q.A.; Byrappa, K.; Chandrashekar, B.N.; Ramakrishna, S.; et al. Novel Green Biomimetic Approach for Synthesis of ZnO-Ag Nanocomposite; Antimicrobial Activity against Food-borne Pathogen, Biocompatibility and Solar Photocatalysis. Sci. Rep. 2019, 9, 8303. [CrossRef] [PubMed]

65. Vinayagam, R.; Pai, S.; Varadavenkatesan, T.; Pugazhendhi, A.; Selvaraj, R. Characterization and photocatalytic activity of ZnO nanoflowers synthesized using Bridelia retusa leaf extract. Appl. Nanosci. 2021. [CrossRef]

66. Pei, Z.; Ding, L.; Hu, J.; Weng, S.; Zheng, Z.; Huang, M.; Liu, P. Defect and its dominance in ZnO films: A new insight into the role of defect over photocatalytic activity. Appl. Catal. B Environ. 2013, 142-143, 736-743. [CrossRef]

67. Rahman, Q.I.; Ahmad, M.; Misra, S.K.; Lohani, M. Effective photocatalytic degradation of rhodamine B dye by ZnO nanoparticles. Mater. Lett. 2013, 91, 170-174. [CrossRef]

68. Benmami, M.; Chhor, K.; Kanaev, A. High photocatalytic activity of monolayer nanocoatings prepared from non-crystalline titanium oxide sol nanoparticles. Chem. Phys. Lett. 2006, 422, 552-557. [CrossRef]

69. Stoyanova, D.; Stambolova, I.; Blaskov, V.; Zaharieva, K.; Avramova, I.; Dimitrov, O.; Vassilev, S.; Eliyas, A.; Nedyalkov, N. Mechanical milling of hydrothermally obtained $\mathrm{CaTiO}_{3}$ powders-Morphology and photocatalytic activity. Nano-Struct. Nano-Objects 2019, 18, 100301. [CrossRef]

70. Guo, S.; Han, S.; Mao, H.; Dong, S.; Wu, C.; Jia, L.; Chi, B.; Pu, J.; Li, J. Structurally controlled ZnO/TiO 2 heterostructures as efficient photocatalysts for hydrogen generation from water without noble metals: The role of microporous amorphous/crystalline composite structure. J. Power Sources 2014, 245, 979-985. [CrossRef]

71. Domaschke, M.; Zhou, X.; Worgen, L.; Romeis, S.; Miehlich, M.; Meyer, K.; Peukert, W.; Schmuki, P. Magneli phases in anatse strongly promote co-catalyst-free photocatalytic hydrogen evolution. ACS Catal. 2019, 9, 3627-3632. [CrossRef]

72. Hurum, D.C.; Agrios, A.G.; Gray, K.A.; Rajh, T.; Thurnauer, M.C. Explaining the Enhanced Photocatalytic Activity of Degussa P25 Mixed-Phase $\mathrm{TiO}_{2}$ Using EPR. J. Phys. Chem. B 2003, 107, 4545-4549. [CrossRef]

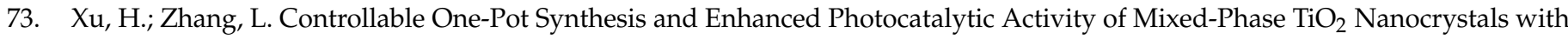
Tunable Brookite/Rutile Ratios. J. Phys. Chem. C 2009, 113, 1785-1790. [CrossRef]

74. Stambolova, I.; Stoyanova, D.; Shipochka, M.; Blaskov, V.; Nihtianova, D.; Markov, P.; Eliyas, A.; Mladenova, R.; Dimitrov, L.; Abrashev, M.; et al. Enhanced effect of combination of new hybrid $\mathrm{TiO}_{2}$ phase and phosphorus dopant on the physicochemical properties and UV/Visible light photocatalytic activity. Mater. Charact. 2021, 172, 110775. [CrossRef]

75. Soto-Robles, C.; Luque, P.; Gómez-Gutiérrez, C.; Nava, O.; Vilchis-Nestor, A.; Lugo, E.; Ranjithkumar, R.; Castro-Beltrán, A. Study on the effect of the concentration of Hibiscus sabdariffa extract on the green synthesis of ZnO nanoparticles. Results Phys. 2019, 15, 102807. [CrossRef]

76. Anwar, F.; Abbas, A.; Mehmood, T.; Gilani, A.; Rehman, N. Mentha: A genus rich in vital nutra-pharmaceuticals-A review. Phytother. Res. 2019, 33, 2548-2570. [CrossRef] 